\title{
The frozen grounds processing with a bucketless bottom rotor
}

\author{
Serik Nurakov ${ }^{1}$ and Talal Awwad ${ }^{1,2 *}$ \\ ${ }^{1}$ L.N. Gumilyov Eurasian National University, Satpayev Str., 2, Astana, Republic of Kazakhstan, \\ 010008 \\ ${ }^{2}$ Damascus University, Syria
}

\begin{abstract}
The analysis of special conditions of buildings construction and transport constructions in difficult geotechnical and severe climatic conditions has been given. It is necessary to have a special working facility for earth excavation implementation. The bucketless bottom rotor with destructive elements in the form of oblique wedges meets these requirements. It allows destroying frozen and strong grounds with the least power-intensive way. The calculation method of ground separation force by angular teeth on the basis of spatial representation of ground failure forces has been given. The calculations have been confirmed with natural experiments of an excavator on frozen grounds.
\end{abstract}

\section{Introduction}

The new mineral deposits development in severe climatic and difficult geotechnical conditions makes necessary of construction and mining operations with new technologies and technical means which allow developing stronger grounds and mountain environments: frozen and rocky grounds, light rocks, minerals, etc.

Consequently, existing methods are being improved and new constructive solutions, development methods and technological processes are being proposed.

The new technical solutions, directed to the creation of a bucketless bottom rotor for the development of strong ground environments, are given in the article: frozen grounds and light rocks $[1,2,3]$. There was destroyed by a slanting wedge as the least power-intensive way of ground development [4] which has not been used to apply in rotor working elements.

The invention nature is clear from fig. 1. The working element includes a bucketless bottom rotor on which teeth, in the form of slanting wedges, located on feed well corners which reduce power consumption and dynamism due to destruction force reduction of the environment and damping of a cross and horizontal fluctuations are fixed. The cutters are set to an angle to a forming rotor feed wells with side and trajectory shift, forward sides of cutters and their cutting edges are designed with unilateral bevels to the middle of the feed well, and back sides of cutters have the platform which projection to the radial plane of rotor is parallel

\footnotetext{
* Corresponding author: dr.awwad.gfce@gmail.com
} 
to the forming feed well. The separation of shaving is made with the least power-intensive slanting semi-free cutting at their movement from top to down concerning a face due to teeth in the form of the slanting wedges located on a rotor with side and trajectory shift. At the same time, the power consumption in comparison with the cutting elements in the form of direct teeth or knives significantly decreases. Forces, which are periodically arising in the cutting course and defiant violent vibrations of a rotor, are damped due to continuous sliding of the tooth back platform on the massif surface of the face ground.

The novelty of a teeth design and process peculiarity of shaving separation from the massif have respectively demanded a new method development of destruction forces analysis as all existing methods include only front cutting by a straight tooth [5, 6,7], and side and normal efforts can be done in percentage ratios of the main - a force tangent component, but these ratios fluctuate in very wide limits and have not that accuracy which can be reached, using new data provided in the present article.

\section{Method}

The following assumptions have been accepted in developing a new method of forces calculation of destruction with the teeth: the developed environment is uniform; ground (rock) separates from the massif in the chip under the breaking-off forces influence; the cutting elements - sharp (without wear); speed influence isn't considered; rotor fluctuations in the vertical and horizontal planes are absent.
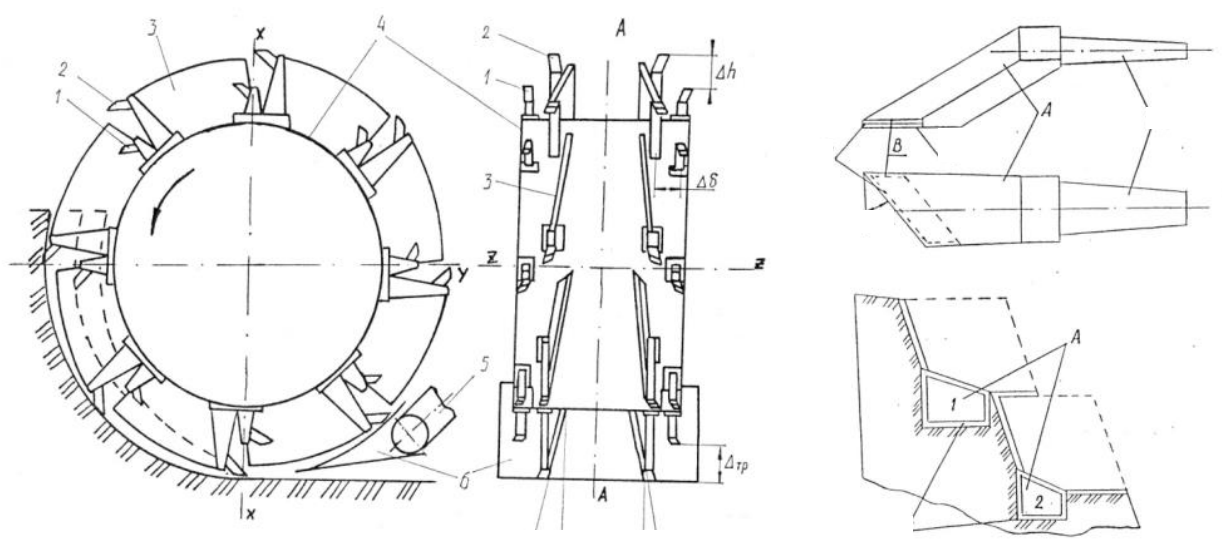

Fig.1. The wheel. Soviet patent №1799413 dated 08.10.1993

We will observe the process of efforts formation on the tooth in the form of a slanting wedge with a slanted forward side and a cutting edge which is at an angle $\varphi_{z x}$ to the cutting direction (fig. 2). The tooth in the form of a sharp wedge with the angle of cutting $\alpha_{\mathrm{p}}$ equal to a point corner, and the back side, which is constantly in contact with a face breast, will be observed. The tooth is set on a rotor so that the projection of a backside to the radial plane is parallel to the forming feed well of a rotor and $\psi=0$. It excludes a back side from contact with a side part of a face at cross-feed of a rotor that reduces side resistance and provides damping of rotor possible fluctuations. 


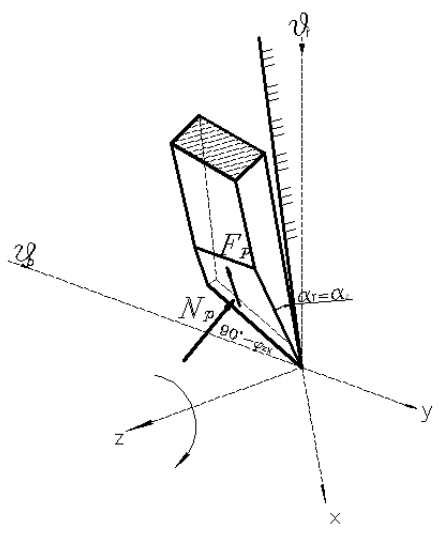

a)

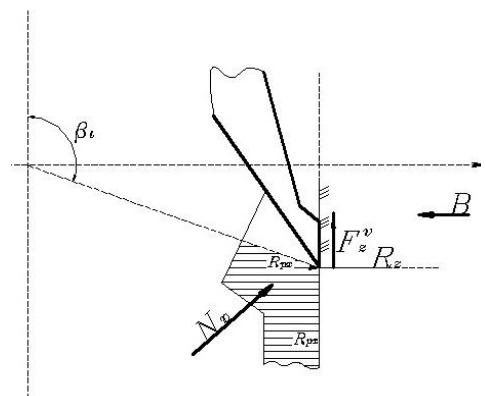

c)

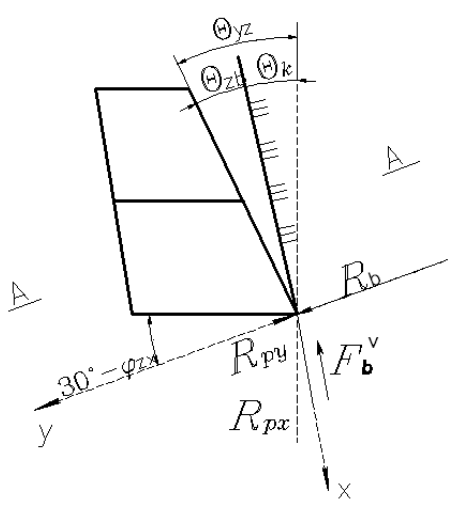

b)

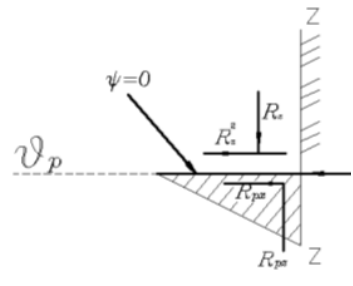

d)

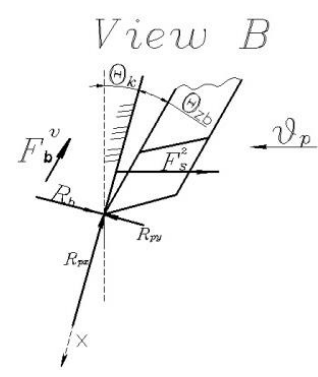

e)

Fig. 2. Forces formation on a tooth in a slanting wedge form, a) tooth view and operating forces in an axonometric; c) tooth projections and forces to axes $\mathrm{x}, \mathrm{y}, \mathrm{z}$; d) section A-A; e) B tooth view

The tooth is set on the feed well at an angle $\theta_{\mathrm{yz}}$ towards side feeding bigger than a kinematic corner $\theta_{k i n}$, thereby providing a back angle of cutting on a side face $\delta_{z b}$. As a result of it, the tooth is in contact with the face only the small site of a side face at an edge.

Tooth of slanting cutting of a rotor of the lower unloading is affected by the following forces: ground resistance force to destruction of $N_{p}$, resistance force to side giving of a rotor of $R_{z}$, tooth release force from friction force face of $F_{p}, F_{b}^{v}, F_{z}^{v}, F_{z}^{g}$, operating in the planes of relevant sides.

The action of all applied forces in three directions can be observed: tangent (along axis $\mathrm{x}$ ), sidelong (along with an axis y) and normal (along with an axis $\mathrm{z}$ ) to tooth movement direction in the separation course of shaving from a face.

The ground resistance force, normal to a forward side of the tooth to the destruction of $N_{p}$ on an axis $\mathrm{x}, \mathrm{y}, \mathrm{z}$. According to the theory of a slanting wedge it is possible to write down, including a tangent component of $R_{p_{\mathrm{x}}}$ to the equal force of destruction and determined by the standard technique, sideward and normal components $R_{p \mathrm{y}}$ and $R_{p z}$ through $R_{p \mathrm{x}}$ :

$$
R_{p \mathrm{y}}=R_{p_{\mathrm{X}}} \operatorname{ctg}\left[\operatorname{arcctg}\left(\frac{\sin \alpha_{p}}{\mu_{M} \sin \omega}+\cos ^{2} \alpha_{p} \operatorname{tg} \varphi_{\mathrm{zx}}\right)+\varphi_{\mathrm{zx}}\right]
$$

and

$$
R_{p z}=R_{p \mathrm{x}} \frac{\cos \alpha_{p}-\mu_{M} \sin \alpha_{p} \cos \omega}{\cos \psi_{1}+\mu_{M} \sin \psi_{1}}
$$


where $\alpha_{\mathrm{p}}$ is a cutting angle, hail; $\varphi_{\mathrm{zx}}$ is an installation angle of a cutting edge in the plan to the cutting direction, a hail; $\mu_{\mathrm{M}}$ is a ground friction coefficient on metal; $\omega$ is a corner between the friction force direction on a forward side $F_{p}$ and a normal to the cutting edge, a hail; $\psi_{1}$ is a corner between force of $\mathrm{Np}$ and an axis $\mathrm{x}$.

The formulas analysis ( 1 ) and (2) shows that at $\varphi=90^{\circ}$ and $\omega=0$ there is a front cutting a flat wedge, and at $\alpha_{p}=90^{\circ}$ and $\omega=90^{\circ}$, there is a process of a cave-in of a slanting stamp. It is certified that widespread front cutting is a special case of the removed correspondences (1) and (2).

The expression of (1) and (2) can be written in a simplified form:

$$
R_{p \mathrm{y}}=K_{\mathrm{y}} R_{p \mathrm{x}} \text { and } R_{p z}=K_{z} R_{p \mathrm{x}}
$$

where

$K_{\mathrm{y}}, \mathrm{K}_{z}$ are the coefficients calculated on the known optimum values of slanting wedge parameters, replacing multipliers in formulas (1) and (2).

We receive in a general view of expression for tangent, sideward and normal force on one a tooth on the basis of initial formulas $(1,2,3)$ and the settlement scheme (fig. 2) after transformation:

$$
\begin{gathered}
P_{\mathrm{\kappa} i}^{\prime}=\left[\mathrm{K}_{F} a_{0} b \sin \beta_{i}+\mathrm{K}_{F} a_{0} b \sin \beta_{i} \mu_{\mathrm{M}} \sqrt{1+\mathrm{K}_{\mathrm{y}}^{2}+\mathrm{K}_{\mathrm{Z}}^{2}} \sin \psi_{1}+\mu_{\mathrm{M}}\left(\sigma_{v} b_{z b} l_{b}-\right.\right. \\
\left.\left.\mathrm{K}_{\mathrm{y}} \mathrm{K}_{F} a_{0} b \sin \beta_{i}\right)+\mu_{\mathrm{M}}\left(\sigma_{v} b_{z z} l_{z}-\mathrm{K}_{z} \mathrm{~K}_{F} a_{0} b \sin \beta_{i}\right)\right] \cos \theta_{k i n} \\
P_{b i}^{\prime}=\left(\sigma_{v} b_{z b} l_{b}-\mathrm{K}_{\mathrm{y}} \mathrm{K}_{F} a_{0} b \sin \beta_{i}\right) \cos \theta_{k i n}, \\
P_{\mathrm{н} i}^{\prime}=\left(\sigma_{v} b_{z z} l_{z}-\mathrm{K}_{\mathrm{z}} \mathrm{K}_{F} a_{0} b \sin \beta_{i}\right) \cos \theta_{k i n} .
\end{gathered}
$$

The removed correspondences for the values of the making cutting forces flowing on an arch of cutting with one tooth allow determining average values of cutting forces on a rotor.

\section{Results}

The average value of a tangent component of cutting force for one turn of a rotor including $a_{i}=a_{0} \sin \beta_{i}$ will be:

$$
\begin{gathered}
P_{k(c p)}=\left[\frac{\kappa_{F} a_{0} b\left(1+\cos \beta_{1}\right) z}{2 \pi}+\frac{\kappa_{F} a_{0} b\left(1+\cos \beta_{1}\right) z \mu_{\mathrm{M}} \sqrt{1+K_{\mathrm{y}}^{2}+K_{z}^{2}} \sin \psi_{1}}{2 \pi}+\mu_{\mathrm{M}}\left(\sigma_{v} b_{z b} l_{v}-\right.\right. \\
-K_{\mathrm{y}} \frac{\kappa_{F} a_{0} b\left(1+\cos \beta_{1}\right) z}{2 \pi}+\mu_{\mathrm{M}}\left(\sigma_{v} b_{z z} l_{z}-K_{\mathrm{y}} \frac{\kappa_{F} a_{0} b\left(1+\cos \beta_{1} z\right.}{2 \pi}\right] \cos \theta,
\end{gathered}
$$

where $\beta_{1}$ is an initial corner on a cutting arch, a hail; $z_{z}$ is a number of teeth on a rotor, item.

The average value of a side component of cutting force will also depend on the shaving thickness changing on a cutting $\operatorname{arch} a_{i}=a_{0} \sin \beta_{i}$ :

$$
P_{b(c p)}=\left(\sigma_{v} b_{z b} l_{v}-\kappa_{\mathrm{y}} \frac{\kappa_{F} a_{0} b\left(1+\cos \beta_{1}\right) z}{2 \pi}\right) \cos \theta_{k i n} .
$$

We remove expression for a normal component of cutting force similarly:

$$
P_{\mathrm{H}(c p)}=\left(\sigma_{v} b_{z z} l_{z}-\kappa_{z} \frac{\kappa_{F} a_{0} b\left(1+\cos \beta_{1}\right) z}{2 \pi}\right) \cos \theta_{k i n} .
$$




\section{Discussion}

The two types of cutting elements have been tested on the frozen ground: the slanting wedges and direct knives reinforced by hard-alloy inserts (fig. 3).

In the course of the experiments, measurements were carried out: the electric power consumed by electric motors of a rotor drive and the rotary platform, registered by N-354 wattmeter recorder; shaving parameters by a ruler, ground density by DORNII dynamic densitometer; experiment time on a stopwatch.

The soil density during tests was $\mathrm{S}=60-80$ of blows, humidity $18-22^{\circ}, \mathrm{t}_{\mathrm{gp}}^{\mathrm{o}}=0,8-2^{\circ} \mathrm{C}$, frost penetration depth $0,65 \mathrm{~m}$, threaded upfront and frost face was developed.

In the course of tests, cutting elements types on a rotor, shaving width, rotation speed of a rotor and a rotary platform was changed. Observations of excavator operation have shown the advantages of cutting elements in the form of slanting wedges which provided the smallest specific force of digging and dynamism of working process, steady process of excavation and lack of fluctuations of a rotor.

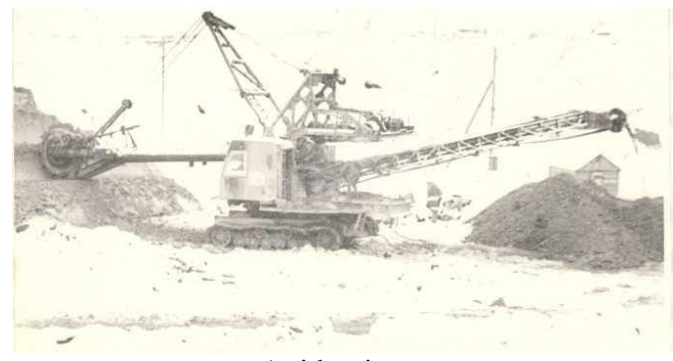

a) side-view

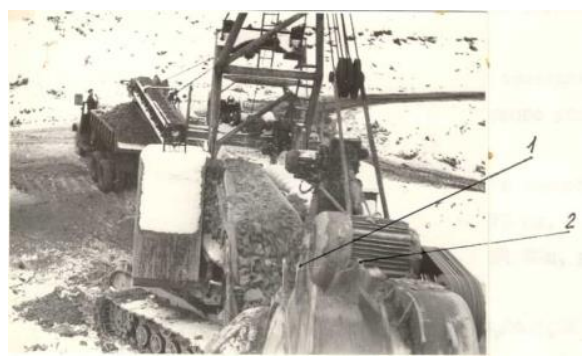

b) top view

Fig. 3. The bucketless wheel excavator during the work in winter conditions, 1 - direct knives with hard-alloy inserts; 2 - teeth in the form of slanting wedges.

The work of excavator has shown the efficiency on frozen soil processing: the excavator has worked productivity during the work with direct knives $-160 \mathrm{~m} / \mathrm{h}$, with the cutting elements slanting wedges $-220 \mathrm{~m} / \mathrm{h}$. without violation of working capacity.

In accordance with any findings, the schedules of specific force dependence of digging have been made. Apparently from fig. 4 the specific force of digging depending on the width and the cross-sectional area of shaving at $\mathrm{a}=80-120 \mathrm{~mm}, \mathrm{~h}=1600 \mathrm{~mm}$ changes at a rotor with slanting wedges limits from 1,12 to $1,34 \mathrm{MPa}$, at a rotor with knives - from 1,2 to 1,5 MPa. Depending on rotor speed within $3,25-4,55 \mathrm{~m} / \mathrm{s}$ the specific effort of digging increases according to the measurements from 1,22 to 1,42 $\mathrm{MPa}$ and from 1,3 to 1,5 $\mathrm{MPa}$ (fig. 5).

These values of the specific force of digging correspond to excavators' indicators with the increased digging force for rocks and coals processing.

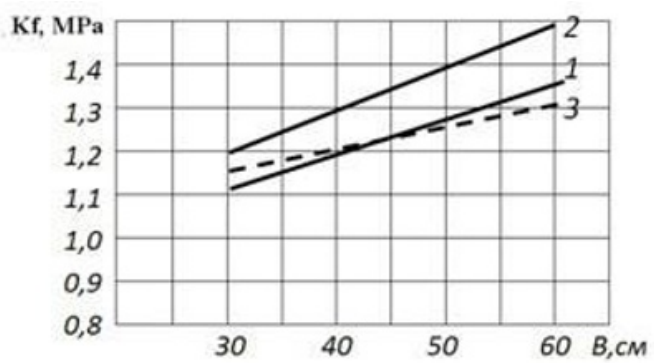

Fig. 4. Dependence of digging specific force from the width and cross-sectional area of shaving, $1-$ slanting step destruction rotor; 2 - a rotor with knives; 3 - calculated values. 


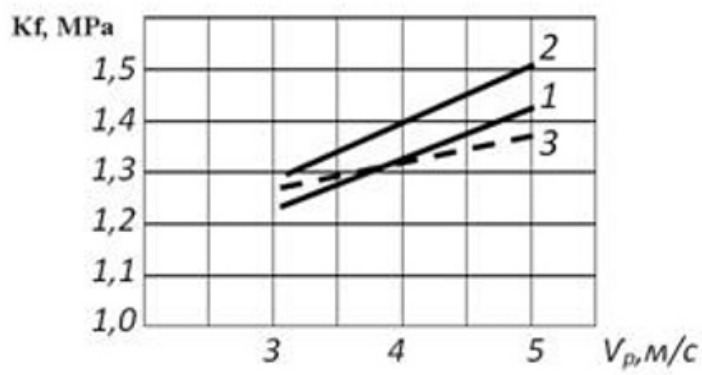

Fig. 5. Dependence of digging specific effort on a rotor rotation speed, 1 - slanting step destruction rotor; 2 -rotor with knives; 3 - calculated values.

The excavator safety operability and lack of rotor arrow fluctuations in the vertical plane have shown a possibility of further force increase of digging on the stronger ground whereas excavators with gravitational rotors in winter conditions sharply reduce productivity, have limited specific digging forces, have a high dynamism and power consumption.

\section{Conclusions}

1) The spatial scheme of destruction forces formation has been considered by a slanting wedge of a bucketless bottom rotor;

2) The calculation method of all three components of tooth cutting forces in the form of a slanting wedge including features of its design, geometrical parameters, the installation angle on the feed well and kinematics of the movement during a shaving separation has been offered;

3) The dependencies for direct calculation of side and normal cutting forces on rotor working element have been received for the first time;

4) The analysis of the removed settlement dependences of a tangent component of tooth destruction force in the form of a slanting wedge has shown that the standard method of force calculation of widespread front destruction by flat tooth is a special case of the offered calculation method.

\section{References}

1. S. Nurakov. The rotor excavator Working element. The patent of the Russian Federation No. 1799413 from 10/8/1993.

2. S. Nurakov. Rotor working element. Patent of the Republic of Kazakhstan for an invention No. 27061 from 7/15/2015, Bulletin No. 7.

3. S. Nurakov, D.B. Uspanov. The teeth attachment fitting of the rotor working element. Patent of the Kazakhstan for an invention No. 27063 from 4/15/2015, Bulletin No. 4.

4. V.P. Goryachkin. Collected works, T.1 and 2. (Selkhozgiz, Moscow, 1965)

5. Yu.A. Vetrov. Ground cutting by digging machines. (Mechanical engineering, Moscow, 1971)

6. T. Awwad, M. Donia, L. Awwad. Procedia Engineering, 189, 525-532 (2017)

7. Awwad T., Gruzin V., Kim V. Current Geotechnical Engineering Aspects of Civil Infrastructures. GeoChina 2018. Sustainable Civil Infrastructures. 13-23. (2018) 